\title{
Boosting Knowledge Through Awareness Raising: An Underexploited Opportunity for Community Forestry in South West Cameroon
}

\author{
Mbunya Francis Nkemnyi ${ }^{1}$, Tom De Herdt ${ }^{1}$, Henry Musoke Semakula ${ }^{2} \&$ Fomengia Dominic Nkenglefac $^{3}$ \\ ${ }^{1}$ Institute of Development Policy and Management (IOB), University of Antwerp, Belgium \\ ${ }^{2}$ School of Environmental Science and Technology, Dalian University of Technology, Dalian \\ ${ }^{3}$ Resource Centre for Environment and Sustainable Development (RCESD), Cameroon \\ Correspondence: Mbunya Francis Nkemnyi, Institute of Development Policy and Management (IOB), University \\ of Antwerp, Lange St. Annastraat 7, 2000 Antwerp, Belgium. Tel: 324-8480-2324. E-mail: \\ nmbunyaf@gmail.com
}

Received: April 9, 2014 Accepted: May 19, 2014 Online Published: May 22, 2014

doi:10.5539/enrr.v4n3p URL: http://dx.doi.org/10.5539/enrr.v4n3p39

\begin{abstract}
Boosting knowledge through awareness raising is important in shaping on why, what, when, where, who and how one can benefit from community forest (CF) resources. Based on this assumption, this study assessed how awareness raising has influenced community participation in community forestry in South West Cameroon, with reference to two case studies. A total of 60 participants selected purposively were involved in this study and primary data was collected using interview guides, focus group discussions and field observations. Repondents' awareness was categorised into five main themes: formation awareness, management committee awareness, management process awareness, rights awareness and benefits sharing awareness. ALAST.ti 5 was used for data analysis and the results revealed that local community members were poorly informed on how the CF came into existence, the main people involved in their management, how they were being managed and on how they could access and benefit from them. Thus, since local community members were less informed, they were unable to participate meaningfully to implementation. In this line, the study argues that for inclusive participation to be enabled in CF implementation in Cameroon, there is an inevitable need to ensure that all intended beneficiaries are well informed on the concept. We recommend that policy interventions should consider strategies that will commit CF managers and other stakeholders to ensure the full awareness of all participants. There is also a need to motivate public debates and research on how local awareness and participation can be sustainably achieved.
\end{abstract}

Keywords: awareness raising, community forestry, local participation, Cameroon

\section{Introduction}

Biodiversity conservation projects and programmes most often interfere and in some cases threaten the livelihoods of the local inhabitants where there are being implemented (Chowdhury \& Ahmed, 2010; Nkemnyi et al., 2013; World Bank, 2007). The way in which different stakeholders participate in development these biodiversity conservation projects is shaped by how they perceive the goals and outcomes of participation. Natural resource management (NRM) needs to capture the multi-dimensional aspects of development in a sustainable way in order to create a balance between environmental conservation and development. Forests are natural resources as well as public goods that need to be managed in the interests of local, regional and global posterity (Yufanyi Movuh, 2013). Despite these arguments, scholars have argued that nature conservation and management has recently done less to support indigenous rights and to facilitate interventions that improve livelihood support (Büscher \& Dressler, 2007; Dressler et al., 2010; Yufanyi Movuh, 2013). In addition, it is also argued that, though the sustainable combination of conservation and development is increasingly being recognised as a priority in NRM, global experiences illustrate that this successful integration of conservation and development continues to be abstract (Davidar et al., 2010; Vliet, 2010). Failure to meet sustainable NRM is attributed to inadequate socio-political and economic institutions that shape the human behaviours in an ecosystem (De Koning \& Cleaver, 2012; Dressler et al., 2010). In most circumstances, poor people are the most affected by unsustainable NRM strategies because they directly rely on these resources, with limited alternatives available to them (Nkemnyi et al., 2011; Sanginga et al., 2010). Thus, their response to the usage of natural resources depends fundamentally on many factors beyond their control (Barrett et al., 2011). In a bid to provide 
solutions to local people's marginalisation in natural resource usage, international development discourse has recently shifted its focus from top-down economic adjustments to participative anti-poverty policies (De Herdt \& Bastiaensen, 2004). This shift hints at an acknowledgement of local complexities within the poverty process and at a need to listen to and develop actions with the local people directly involved. However, for local people to actively and meaningfully participate in NRM, they have to be fully aware of the management processes and the policies governing the resources in question (d'Aquino \& Bah, 2013; Danielsen et al., 2008). Most often NRM and environmental policies are not in line with indigenous knowledge and practices (Zoa, 2009). The sustainability of participatory management systems require the reconciliation of modern legal constructs with customary perceptions of forestlands, natural resources and the community (Ezebilo, 2012; Zoa, 2009). This warrants policy makers and implementers to put in concerted efforts by conscientiously drawing local attention to policies governing natural resources and how they can participate in the whole process.

In Cameroon, a Community Forest (CF) is defined as a forest $\leq 5,000$ hectares in size in the non-permanent domain (Note 1) that is subjected to a management agreement between a village or a community and the administration (Ministry of Forestry and Wildlife - MINFOF) in charge of forests (Djeumo, 2001; Alemagi, 2011). Community forests are supposed to have a simple action plan for their effective management and conservation and the exploitation activities must be in the interests of the community concerned. All products therein are considered as properties of the community concerned with the exception of those forbidden by law (Ezzine De Blas et al., 2009). Prior to Cameroon's colonisation by the Germans, forest management was mainly 'clanic ownership' (Yufanyi Movuh, 2012; Brown \& Lassoie, 2010). When the Germans colonised Cameroon, they claimed all the forests and stopped further migrations that were a custom of clans and lineage while forcing people to resettle along the roads in newly created villages. This shifted management from customary forest governance to modern legal governance (Yufanyi Movuh, 2012). The 1994 Cameroon forestry law saw the need to restore community rights and benefits to forest resources by introducing the CF concept (Djeumo, 2001; Ndibi \& Kay, 1999; Yufanyi Movuh, 2012). This concept was aimed at decentralising forest governance by granting some rights to local community members and including them in forest resources management. Several studies have been carried out to evaluate whether this program yielded some benefits or not. A study by Alemagi (2011) indicates that community forestry implementation led to some progress in some areas but it was hampered by a series of socio-economic and ecological challenges which are still very visible. These included corruption, inadequate capital and technical expertise for producing value-added forest products, illegal logging, insufficient research, management conflicts, and inadequate monitoring. While other studies did not record significant successful implementation stories (Ezzine de Blas et al., 2011; Oyono, 2005; Maryudi et al., 2012; Yufanyi Movuh \& Schusser, 2012; Yufanyi Movuh, 2013). From the review of these studies, it was noted that assessment of community awareness about CF implementation was not adequately addressed yet it is one of the key components in sustainable CF management. The key argument of this study assumes that awareness raising and access to knowledge is important in shaping who can benefit from resources (Ribot \& Peluso, 2003). To bridge this knowledge gap, this study aimed at investigating local peoples' knowledge on the concept CF and how this knowledge shaped CF implementation, benefit sharing, access and management.

\section{Materials and Methodology}

\subsection{The Study Area}

Cameroon is located between West and Central Africa at the extreme north-eastern end of the Gulf of Guinea (Ako et al., 2009). It has a total surface area of about $475,650 \mathrm{~km}^{2}$ and by 2009 , Cameroon's population was 19.93 million (Note 2). Cameroon's landscape is distinguished by five main physical features namely; the Coastal Lowlands, the Southern Plateau, the Adamawa Plateau, the Western Highlands, and the Northern Lowlands (Ako et al., 2009). The vegetation is dominated by equatorial forests in the equatorial zone, mangrove forests in the coastal areas, and guinea savannah covering the rest of the zones. The vegetation is mainly Sudan savannah and Sahel savannah is in the extreme north portion of the country which is a tropical climate zone (Singer, 2008). Cameroon comprises of three main climatic zones; the equatorial climate, the equatorial transition climate and the tropical climate (Ako et al., 2009).

Two sites with a community forest were purposely selected for this study, and these included the Bimbia Bonadikombo community forest (BBCF) and the Tinto community forest (TCF) (Figure 1). These two study areas were selected because of their socio-economic characteristics that were important in understanding implementation of CF. In particular, these two sites were selected based on the fact that they had both existed for more than 10 years, a time duration we considered to be sufficient to evaluating peoples' knowledge regarding $\mathrm{CF}$ implementation. The $\mathrm{BBCF}$ is located in an urban periphery and is open to more public interests and conservation attention compared to the TCF. The BBCF created in 2002, is situated at Fako Division, South West 
Region of Cameroon and has a surface area of 3.735 ha (Ahimin \& Mbolo, 2010). Six main vegetation types that include coastal bar forest, mangrove, littoral vegetation, freshwater swamp forest, freshwater ecosystems and lowland forest dominate the BBCF. Rainfall, temperature and humidity are high (Minang, 2003). Annual rainfall is between 4000 and $5000 \mathrm{~mm}$ per annum. A short dry season is experienced between December and February. Humidity in the area is usually between $75-80 \%$. The community is peri-urban in character, located on the fringes of the Limbe (Victoria) urban community. The BBCF comprises five villages (Bonadikombo, Bonabile, Bonangombe, Liwanda, Dikolo). On the other hand, the Tinto community forest is situated in Manyu Division, South West Region of Cameroon. It was created in 1999 and covers a surface area of 2.950 hectares. The forest area is well-drained with an average elevation of about $160 \mathrm{~m}$ above sea (Minang, 2003). It has an average rainfall of about $2000 \mathrm{~mm}$ per year. A short dry season occurs between November and March. Tinto falls within the rich evergreen forest areas of Cameroon known for their endemic species. The adjacent inhabitants of the forest are between 1700-2000 distributed across three villages of the same clan: Tinto Mbo, Tinto Wilier and Tinto kilier (Ngendakumana et al., 2013).
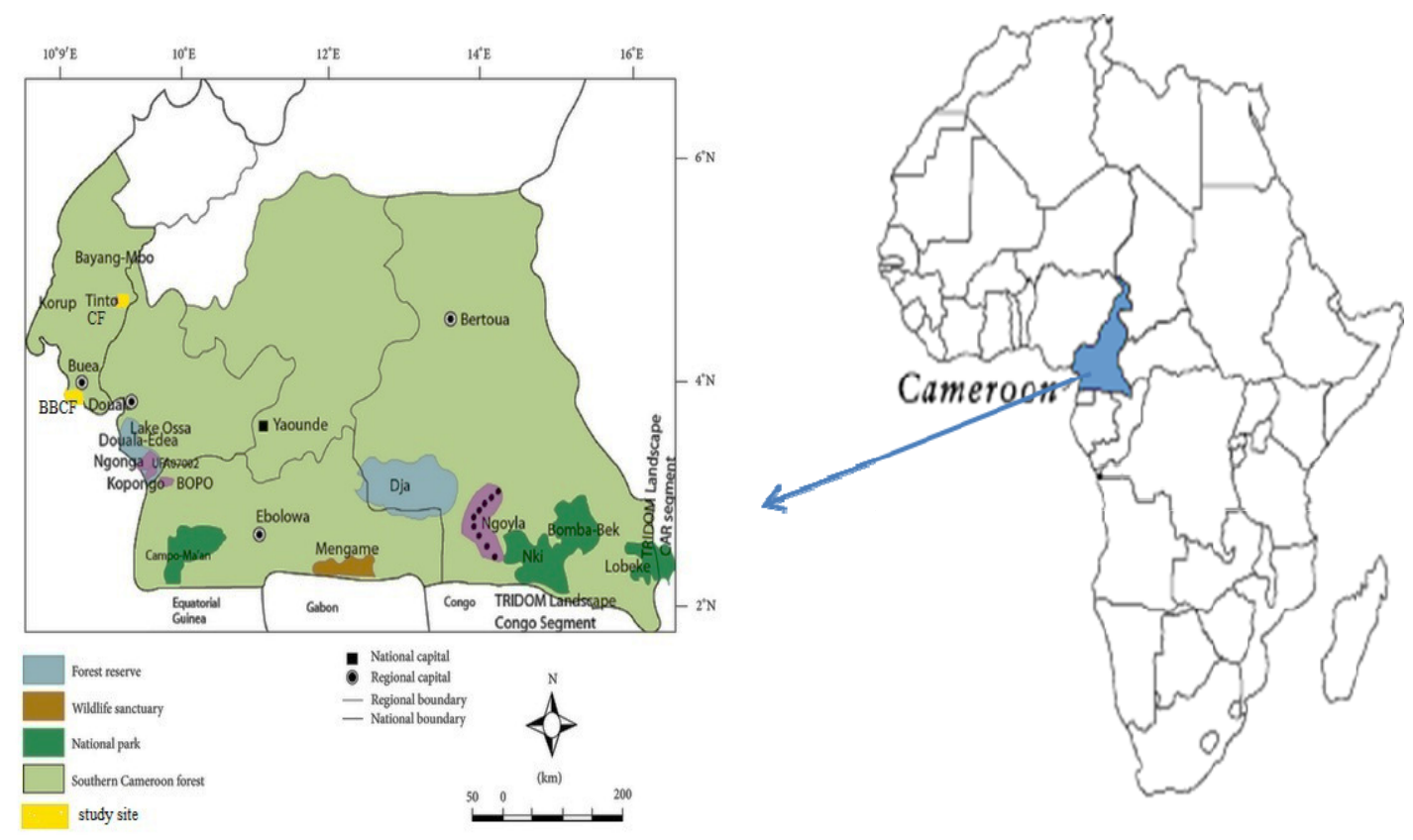

Figure 1. Location of the study area in Cameroon, Africa

Source: Adapted and modified from (Ngendakumana et al., 2013).

\subsection{Research Process and Data Collection Techniques}

In selecting the studied community, we took into consideration two main variables: the period of existence of the community forests and the accessibility of the CF by the researchers. We were interested in CFs that had existed for more than 10 years in order to adequately assess how awareness raising had shaped the implementation process. The selected duration was perceived by the research as sufficient for CF coordinators to have had enough experience or to adapt to appropriate implementation strategies. This study considered the right to awareness of community members as one of the important components to the successful implementation of CF.

This study adopted a qualitative methodology and to a small extent, a quantitative methodology which was used to cater for the social and demographic characteristics of respondents. Qualitative methodology was used because it is vital when studying human beings and their worlds from their own perspective (Holt-Jensen, 1999). In other words, it helped the researchers to understand the nature of social reality regarding CF implementation as perceived by the local people.

This study is informed by two data sources. First, it utilised a diversity of secondary data ranging from books, scientific articles and reports. These were used in order to have an in-depth understanding of how scientific knowledge has been advancing over time regarding biodiversity conservation and CF implementation. The 
review of these literature also helped in identifying knowledge gaps that guided the structuring of this study as well as the design of primary data collection tools. These publications were obtained from online journals and google search engine using keywords and combination of keywords related to CF and biodiversity conservation. Arguments obtained from the secondary data review were also used to discuss our study findings, and this enabled us to extrapolate our arguments to other cases of CF in Cameroon and beyond with confidence.

Secondly, the paper is also supported by primary data. Based on the reviewed secondary data and the gaps identified, primary data collection tools were designed in way that helped to bridge the identified knowledge gaps. Primary data for this study was collected between the months of January and July 2013 Primary data collection tools designed and used to get valid, reliable and diverse construction of realities regarding CF implementation and people's knowledge included interview guides, focus-group discussions, and field observation check lists.

Interview guides were used during the in-depth interviews with respondents. Interviewing is an important tool for data collection and helps researchers to understand the world from the subject's or respondent's point of view while unfolding meaning of people's experiences and uncovering their life world (Bloomberg \& Volpe, 2008).

The in-depth interviews were subjected to 60 respondents and these were selected purposively because of their long stay in the communities as well as their knowledge and experience regarding CF implementation. Each study site (CF) consisted of villages from which 30 key informants were selected. At each village, key informants were selected to participate in the study with the help of local field assistants and the community heads. Interviewees were selected to represent the following categories of persons: forest management committee, local development council, elites, women, youths, farmers, local government staff and local investors. We ensured that interviewees were uniformly distributed across these categories. To evaluate interviewees' awareness, the selected participants were asked questions about the formation of the CF, the persons involved in management, the management processes, the benefits community members receive as a result of the $\mathrm{CF}$ and their overall evaluation of the $\mathrm{CF}$ concept as a whole. All interviews were recorded using a voice recorder and later transcribed for further analysis. The use of a voice recorder shortened the interview period and enabled follow-up questions arising from the discussions to be posed without interruption, which is often the case for manual interviewing. The interviews followed more of a discussion session between the interviewers and the interviewees. The interview method was appropriate in this study as it facilitated in-depth probing and clarification of concepts to respondents thus making it easy to obtain the required information. At the end of each day, all interviews were transcribed into a notebook with the help of the interview guides.

Throughout the interviewing process we were able to understand the dynamics of CF implementation and we drew informative conclusions on how awareness raising influenced the implementation of $\mathrm{CF}$ in the studied areas.

In addition to interviews, two focus group discussions were held, one in each of the study sites. In the BBCF, we had 12 participants (two forest management committee members, two local government representatives, one village development council member, two youths, two men and two women who were all farmers, and one elite) and in the TCF we had nine participants (two forest management committee members, one local government representatives, one youths, two men and two women who were all farmers, and one local investor). The focus group discussions provided a platform where participants raised arguments and clarified each other on their views. The FGDs focused on issues related to local awareness on the concept of CF. Discussions were guided by questions relating on how well community members were informed about the formation of the $\mathrm{CF}$ and the management processes, how benefits were being shared, how awareness raising was executed, who were the main drivers of awareness raising on $\mathrm{CF}$ and how awareness raising had contributed to $\mathrm{CF}$ management. The principal investigator chaired all the discussions while two field assistants took notes of key arguments raised in line with the research subject. A voice recorder was also used to record the discussion sessions which were later transcribed. The voice recorder facilitated the analysis of unclear notes taking during the discussions. Furthermore, field observation enabled the researcher to be able to evaluate people's attitudes and general perceptions from a wider perspective. Participatory observation enabled the collection/validation of data collected during interviews and focus group discussions. This method also enabled the research team to get more detailed and context information which was not covered by both the FDGs and the interviews. Thus, by observing, we were able to reconcile the information gathered and the field situation.

\subsection{Data Analysis}

Quantitative data was subjected to descriptive analysis with a major focus on the demography data of the participants that were involved in the study. The analysis of this information was relevant to aid the explanation 
of some qualitative results obtained during this study. Qualitative data analysis made used of ATLAS.ti 5. ATLAS.ti 5 ensured accurate and high quality reporting of qualitative data. It enabled aggregation of similar arguments and the establishment of relationships between arguments. Using this software, we created five free codes guided by the major themes in the transcripts (formation awareness, management committee awareness, management process awareness, rights awareness and benefits sharing awareness). These free codes were later assigned to the themes of the research using the command 'code by list'. This enabled the clustering and comparison of responses from our two studied sites. Sub-codes were further developed for each themes based on the content of the transcripts using the 'open coding command'. The sub-codes helped in the assignment of results into gender responses, response by community, response by age group, level of education amongst others. The creation of sub-codes was necessary to enable an analytical view of the research subject. A critical analysis of the themes was then performed and relationships established.

\subsection{Limitation of the Study}

This study was limited to Cameroon and in particular the South West Region of Cameroon where we selected our study sites. We do not claim the results to have broader validity mainly because perceptions vary across people and cultures. However, other case studies reporting on similar situations can gain some useful insights from this study. The results represent participants' responses at the period of data collection, which are liable to change over time and circumstances. In addition, the study focused only on limited aspects (impact of awareness and local perceptions) influencing implementation sustainability in CF in Cameroon. The evaluation of aspects influencing sustainable management in community forestry may produce diverse results with new findings, which may not be necessarily discussed in this paper. However, in the discussion section, the study relate most of it findings to related researches on community forestry in Cameroon, which permits the readers to have an overview of the situation in Cameroon.

\section{Results}

\subsection{Demographic Characteristic of Respondents}

Individual characteristics are liable to influence social and environmental relationships. Thus, a demographic study of the sampled population is very relevant in explaining these relationships. In Table 1 below, the demographic information of the interviewees is presented. Subsequent analyses in this study will constantly refer to this demographic information. 
Table 1. Demographic information of respondents

\begin{tabular}{|c|c|c|c|c|c|}
\hline \multicolumn{2}{|c|}{ Characteristics } & \multicolumn{2}{|c|}{$\begin{array}{c}\text { Bimbia Bonadikombo } \\
\text { Community Forest }\end{array}$} & \multicolumn{2}{|c|}{ Tinto Community Forest } \\
\hline & & Total Count $(n=30)$ & $\%$ & Total Count $(n=30)$ & $\%$ \\
\hline \multirow{2}{*}{ Gender } & Male & 19 & 63.3 & 20 & 66.7 \\
\hline & Female & 11 & 36.7 & 10 & 33.3 \\
\hline \multirow{4}{*}{ Age Range } & $<20$ & 2 & 6.6 & 1 & 3.3 \\
\hline & $20-29$ & 7 & 23.3 & 10 & 33.3 \\
\hline & $30-39$ & 6 & 20 & 11 & 36.7 \\
\hline & 40 and above & 15 & 50 & 8 & 26.7 \\
\hline \multirow{4}{*}{$\begin{array}{c}\text { Main } \\
\text { Occupation }\end{array}$} & Farmer/Fisherman & 20 & 66.7 & 17 & 56.7 \\
\hline & Civil servant & 6 & 20 & 6 & 20 \\
\hline & Business man & 4 & 13.3 & 5 & 16.7 \\
\hline & Student & 0 & 0 & 2 & 6.6 \\
\hline \multirow{5}{*}{ Education } & No education & 0 & 0 & 0 & 0 \\
\hline & Primary education & 17 & 56.7 & 14 & 46.7 \\
\hline & Secondary Education & 8 & 26.7 & 7 & 23.3 \\
\hline & High school & 3 & 10 & 5 & 16.7 \\
\hline & University Education & 2 & 6.6 & 4 & 13.3 \\
\hline \multirow{3}{*}{ Family Size } & $<3$ & 7 & 23.3 & 5 & 16.7 \\
\hline & $3-5$ & 9 & 30 & 10 & 33.3 \\
\hline & $>5$ & 14 & 46.7 & 15 & 50 \\
\hline \multirow{3}{*}{$\begin{array}{l}\text { Length of Stay } \\
\text { in Community }\end{array}$} & $<10$ & 6 & 20 & 6 & 20 \\
\hline & $10-19$ & 3 & 10 & 7 & 23.2 \\
\hline & 20 and above & 21 & 70 & 17 & 56.7 \\
\hline
\end{tabular}

The demographic characteristics show that more male respondents $(63.3 \%$ and $66.7 \%$ respectively in BBCF and TCF) participated in the study compared to female respondents. More than $55 \%$ of interviewees from both study sites were above 30 years and had lived in the community for more than 20 years. The fact that they lived in these communities before the creation of CF justifies why they were selected as key informants. Given that community forestry is supposed to involve all local people as stated by the legislation, the majority of the respondents were famers/fishermen (66.7\% and 56.7\% respectively in the BBCF and the TCF). All interviewees have attended at least primary education. In addition, $90 \%$ of respondents who had attended at least high school education, were working with the local government or were self-employed in the small business sectors Most respondents had a family size greater than five ( $46.6 \%$ and $50 \%$ in the BBCF and TCF respectively).

\subsection{Awareness on the Community Forest Concept}

Our evaluation of local knowledge was based on how well interviewees were informed on the concept of CF and their rights to benefit from them. This study categorised awareness into different themes: awareness on the formation of the CF; awareness on the forest management committee, awareness on the management process and awareness on rights and benefit sharing. This study found out that local community members had poor knowledge on the concept of $\mathrm{CF}$ and its general implementation.

Awareness on the formation of the CF: In the TCF, $90 \%$ of the studied population were aware that there is a CF in Tinto while $10 \%$ did not know if the forest in question was a CF or not. Further questioning on the formation of the Tinto CF revealed that $73.3 \%$ of the interviewees had very poor knowledge on how the status of CF came about. This result was supported by diverse responses obtained when we asked interviewees to state how the CF status came about. Responses came from the villagers, the Tinto clan, the Tinto common Initiative Group, the 
Divisional Officer of Tinto, and the Village Secretary. However, $26.7 \%$ of the interviewees who were later identified as being part of the forest management committee or working with the local government, were well informed on the formation of the Tinto CF. The latter interviewees recounted in details how Tinto CF formation process began in November 1999 with the assistance from the Living Earth Foundation (a local based non-profit organization) and completed in December 2002 with a surface area of 2.950 hectares of forest assigned as CF. On the other hand, all interviewees in the Bimbia-Bonadikombo (BB) were aware of the existence of the BBCF. However, $60 \%$ had little knowledge on the persons that facilitated the formation of the CF. To this latter interviewees, they were aware that CF came about as a result of the efforts of the BB development council and some elites. They also had very little information about who were the people constituting this development council. Notwithstanding, 40\% could explain that the BBCF formation process began in 1998 and was facilitated the Mount Cameroon Project alongside some influential stakeholders (elites) of the BB community. The process was completed in 2002 with a total surface area of 3.735 hectares.

Awareness on Management and the Forest management Committee (FMC): By posing the question, "who are the persons involved in the management of the CF", the responses followed a similar trend as those obtained above on the formation of CF. Those who were well informed about the formation of the CF were also well informed about the composition of the FMC and the management of the CF. In the Tinto community, 16.7\% taught the management of the $\mathrm{CF}$ and this was done by a single person (the village secretary, as they termed it). Similarly, $73.3 \%$ of the interviewees in the Tinto community did not take part in the election of the FMC. In the BB community, $60 \%$ of the participants who had little knowledge on the formation of the CF also had little knowledge of the FMC and the CF management. They were aware that, the CF was managed by the chiefs, elites, the Limbe III Council and some selected members of the community. However, they were not well informed about the persons representing the interests of the groups listed above nor well they informed of the management processes. One of the interviewees from the local government category reported that

... there is a lot of conflicts about who is the right person to issue permission for the exploitation of resources in the CF. At times, the president of the development may sign permission for exploitation and the Limbe III Council refuses to recognise the permission. They have also been cases where the Council permissions are not recognised by the chiefs, and this has been a source of management conflict in the $B B C F \ldots$

Awareness on rights and benefit sharing: By initially asking the interviewees if their rights were protected by the FMC, the result shows that $86.7 \%$ and $56.7 \%$ in the TCF and BBCF respectively accepted that their rights to benefit from $\mathrm{CF}$ were protected by the FMC. However, with a list of follow-up questions on how these rights and benefits were achieved and shared, they ended up attesting that, what they understood as rights were not benefits rights as in the context of $\mathrm{CF}$ specified in this study. To interviewees, the protection of rights was viewed from the context that, they were no major overlaps between their forest-based activities and the activities of the CF. On the other hand, minority of the interviewees $(43.3 \%$ of the BBCF and $13.3 \%)$ argued that the benefits and rights of local community members were not protected. They supported their argument by pointing out that access to explore income generating forest resources like timber, charcoal burning, non-timber forest products (particularly Prunus africana) was not by merit but characterized with a lot of bribery and corruption and only those who could pay "the price" or those in high administrative positions were given access to resource exploitation. One of the interviewee from the elites category reported that "... local people cannot fight for their right and benefits to CF because they do not even understand what the law says about it ...".

In addition, apart from arguing that most participants' rights were not protected, more than $70.0 \%$ of the interviewees also noted that management was not participatory. They argued that many potential stakeholders were usually left out. These included farmers, women and hunters who were based in the community. Based on this observation, one of the interviewees from farmers' category stated that “... we are side-lined simply for the fact that we cannot read nor write ..."

Field observation and arguments from the focus group discussions also fall in line with the above results and further showed that community member who were well informed about the concept of $\mathrm{CF}$ and engaged in $\mathrm{CF}$ management in one way or the other were informed through their personal efforts and other means and not due to the FMC effort. For instant, the presence and activities of non-profit organisations and researchers working in the BBCF comparatively improved local awareness on CF. According to one of the participants of the focus group discussions in the $\mathrm{BB}$ community he reported that 
“... many people have been coming and asking us questions about CF and through that we became more aware on what it was all about. The FMC has never sat down to educate us on what it was all about or on how they managed the forest ..."

This study did not also record any awareness programmes which were designed to improve community knowledge on community forestry and to enable their full participation.

\subsection{Local Community Perception Based on Awareness}

This study noted that the variation in local perceptions on CF was directly proportional to interviewees' knowledge on the objectives of CF, its subsequent implementation and on the benefits individuals received from them. In addition, there were also differences in gender perceptions concerning forest usage. For instant, most female interviewees were less bothered about issues of CF. They were more concerned about the availability of farming land that could enable them to sustain their household needs. However, we also noted a clear difference in interests between more and less educated female interviewees. The more educated women understood the concept of $\mathrm{CF}$ and issues related to forest management and could give valuable arguments on forest management They equally argued for the rights of women to participate in forest management compared to their less educated female counterparts and could point out that women were poorly represented in forest management issues in the studied sites.

This study also considered how local people perceptions on their rights and benefits from forests have changed after the formation of CF. The results showed that there was no major change in perceptions on forest rights and benefits to most interviewees ( $73.3 \%$ and $76.7 \%$ respectively in the BBCF and the TCF). This was supported by the argument that most local people's forest-based activities do not seem to have been affected by the new arrangement (CF). This was also the reason most interviewees thought that their rights were protected. Majority of the interviewees were less interested in the activities of the CF. However, according to their observation, they felt $\mathrm{CF}$ in question were poorly managed. They were not satisfied with the contribution of CF towards local wellbeing so far. On the other hand, $26.7 \%$ and $23.3 \%$ of the interviewees in the BBCF and the TCF respectively, felt that CF had contributed to the development of communities involved. Raising this argument in the focus group discussions, the persons that supported the view that CF had contributed to local development argued that the $\mathrm{CF}$ were serving as touristic and research sites and some community members were benefiting as field assistants and porters. The timber exploitation sector provided employment opportunities for the local people and the forests also provided timber for the construction of houses as well as providing medicinal plants to the local community. Confronted with the above claims, those who were of the contrary opinion argued that all the benefits listed above were possible prior to the presence of the CF. The latter persons argued that, they would have expected income raised from forest exploitation to be invested to improve the livelihoods of the local people; for instance by providing loans to assist local people to invest in improved farming practices and micro enterprises, which to the best of their knowledge had not occurred.

\section{Discussion}

The results of this study showed that awareness on the concept of community forest was higher in the BBCF compared to the TCF. This is probably because the high public interest (more presence of researchers and non-profit organisations) in BBCF has generated in one way or the other higher awareness to community members on the concept of CF compared to the TCF. Thus, participants in the BBCF were in a better position to understand local community rights to community forestry. Notwithstanding, majority $(73.3 \%$ and $76.7 \%$ respectively in the BBCF and the TCF) of the studied population have very little knowledge of the concept of CF. They knew little about their rights and benefits from CF and thus, were less interested in participating in the implementation process. They considered it as a government project rather than a community project as stated in the purpose of CF. In this line, management was left in the hands of FMC, the local council and private investors who were interested in commercialising forest products. The above argument is in line with the study conducted by Ribot and Peluso (2003), where it is indicated that access to knowledge is important in shaping who can benefit from resources. The latter argument is also linked to the results of this study, which shows that some community members were side-lined from participating in CF because they could neither read nor write. This also made them incapable of knowing what the CF policy said about community members' benefits from forest exploitations. This indeed limited them from participating in CF implementation.

Though the introduction of CF into the 1994 Cameroon forestry legislation was seen as an opportunity that would bring forest management to benefit the local people, wide spread management conflicts and failure all over the country has shown that these broad expectations have not been met (Ezzine de Blas et al., 2011; Oyono et al., 2012; Samndong \& Vatn, 2012; Yufanyi Movuh, 2013). This study identified inadequate awareness on the 
concept of $\mathrm{CF}$ as one of the major challenges to CF implementation. This study argues that if community members do not have an in-depth knowledge on the concept of $\mathrm{CF}$, they will be unable to participate meaningfully to its implementation. Their ability to contest rights and benefits from $\mathrm{CF}$ will depend on the knowledge of CF concept. In the same line, it is also argued that CF managers on their own part do not even possess copies of CF policy (Ngendakumana et al., 2013). This is possibly contributed by the fact that they are less interested in motivating local awareness and participation to CF. In addition, this study also argues that forest managers are not a representation of the local populations given that interviewees attested not taking part in their election into power. But the democratic election of community forest managers is clearly spelled out in the 1994 forestry legislation (Oyono \& Efoua, 2006). Oyono and Efoua (2006) also argued that FMC members are often retired civil servants who have returned to their villages and educated young men who have not been able to find employment in urban areas. These forestry elites often dominate the process and exclude other people from benefiting from the services of community forestry (Oyono, 2005; Oyono \& Efoua, 2006). Evidence from this study also showed that more than $70 \%$ of the participants who were supposed to be directly involved in the CF implementation had poor knowledge on the FMC and how they implemented the management forest resources. This is linked to the arguments that local communities are not benefiting from CF because the institutions concerned are still centralised and favour only a minority population (Alemagi, 2011; Beauchamp \& Ingram, 2011; Oyono et al., 2012; Yufanyi Movuh, 2013). This minority population is usually not fully aware of the local issues and the forest policy itself and as such cannot develop appropriate strategies for sustainable CF implementation (Ngendakumana et al., 2013).

For sustainable management to be achieved, many actors and variables are needed (Pendergast et al., 2011). Arguments in this study and argument from related scholars revealed that CF implementation in Cameroon is still faced with a lot of challenges that need immediate attention. The scope of diverse actors and variables necessary for sustainable implementation is still narrow. The ability of participatory dialogue involving community members, government, and other relevant actors and stakeholders, which is needed to develop coherent rules and principles on how to design and implement locally adapted mitigation actions in CF do not yet exist (Ngendakumana et al., 2013). Individuals involved in CF seem to be more interested in personal financial benefits and ignore the general purpose of CF. This also explain why the forest managers were less motivated to raise community members awareness on $\mathrm{CF}$ and to enable participatory management. This is argued to be one of the main reason community forestry has been unable to improve local livelihood and wellbeing as intended (Beauchamp \& Ingram, 2011). In addition, the existence of powerful stakeholders' influence in centralising management (Yufanyi Movuh \& Schusser, 2012) and the lack of accountability and transparency in management (Ezzine de Blas et al., 2011) amongst others, have also be reported as other drawbacks leading to $\mathrm{CF}$ failures.

\section{Conclusion}

Using in-depth interviews, focus group discussions and field observations, the findings of this study argues that local community members are poorly informed on how the CF came into existence, the main persons involved in their management, how they were managed and on their rights and benefits from CF. Since the intended beneficiary were less informed on the concept in its entity, they were unable to participate meaningfully to its implementation given that, the ability to contest rights and benefits depends on the knowledge of the participants (Ribot \& Peluso, 2003). This implies an increased in local awareness on the concept of CF will eventually increase their knowledge and ability to participate in the implementation. Poor knowledge on community forestry is a limitation to participatory management as shown in this study. The fact that $86.7 \%$ and $56.7 \%$ of the interviewees in the TCF and BBCF respectively accepted initially that their rights and benefits from CF were protected by the FMC but later rejected this position after further probing, shows a big challenge regarding $\mathrm{CF}$ implementation. If they were aware of these rights and benefits, they would stand for them, and these would motivate them to participate actively in the implementation process. Given that most of the intended beneficiary were not actually benefiting, partly because of lack of knowledge as define by this study, management was left in the hands of few individuals with high interests in the commercialisation of forestry products. In this light, it can also be argued that CF plays a very small role in contributing to community wellbeing as participation is not inclusive. Though many studies on $\mathrm{CF}$ in Cameroon have argued implementation failure to be linked to poor institutional arrangement, leading to corruption, conflicts, poor accountability and lack of complete decentralisation of power that transfer all rights and benefits to the implementation community (Alemagi, 2011; Beauchamp \& Ingram, 2011; Ezzine de Blas et al., 2011; Ngendakumana et al., 2013; Oyono et al., 2012; Yufanyi Movuh, 2013), the argument that increasing local awareness and knowledge on the concept have been highly ignore. This study argues that for inclusive participation to be enabled in CF in Cameroon there is an 
inevitable need to ensure that all intended beneficiaries should be well informed on the concept and it implementation. In the same vein, we recommend that policy intervention should consider strategies that will commit CF managers and other stakeholders to ensure the full awareness of all participants. There is also the need to motivate public debates and research on how local awareness and participant can be achieved in CF implementation.

\section{Acknowledgements}

We will like to thanks the field assistants (Neba Celestine and Chopjou Catherine) who assisted in data collection. Our appreciation also goes to the community members who provided us with the information reported in this study by participating in our interviews. We will also like to thank the anonymous reviewers for their comments and advise that contributed to the final version of this manuscript.

\section{References}

Ahimin, A. O., \& Mbolo, M. (2010). Process in the High Conservation Value (Hcv) Concept Within Community-Managed Forests: Case Study of Copal and Bb Community Forests in Cameroon. Journal of Environmental Assessment Policy and Management, 12(2), 215-237. http://dx.doi.org/10.1142/S1464333210003577

Ako, A. A., Eyong, G. E. T., \& Nkeng, G. E. (2009). Water Resources Management and Integrated Water Resources Management (IWRM) in Cameroon. Water Resources Management, 24(5), 871-888. http://dx.doi.org/10.1007/s11269-009-9476-4

Alemagi, D. (2011). Sustainable development in Cameroon's forestry sector: Progress, challenges, and strategies for improvement. African Journal of Environmental Science and Technology, 5(2), 65-72.

Barrett, C. B., Travis, A. J., \& Dasgupta, P. (2011). On biodiversity conservation and poverty traps. Proceedings of the National Academy of Sciences of the United States of America, 108(34), 13907-12. http://dx.doi.org/10.1073/pnas.1011521108

Beauchamp, E., \& Ingram, V. (2011). Impacts of community forests on livelihoods in Cameroon: lessons from two case studies. International Forestry Review, 13(4), 389-403. http://dx.doi.org/10.1505/146554811798811371

Bloomberg, L. D., \& Volpe, M. (2008). Completing Your Qualitative Dissertation: A Roadmap from Beginning to End. Thousand Oaks, CA: Sage Publications Inc.

Brown, H. C. P., \& Lassoie, J. P. (2010). Institutional choice and local legitimacy in community-based forest management: lessons from Cameroon. Environmental Conservation, 37(3), 261-269. http://dx.doi.org/10.1017/S0376892910000603

Büscher, B., \& Dressler, W. (2007). Linking Neoprotectionism and Environmental Governance: On the Rapidly Increasing Tensions between Actors in the Environment-Development Nexus. Conservation and Society, 5(4), 586-611.

Chowdhury, M. E., \& Ahmed, S. (2010). Poverty-environment nexus: an investigation of linkage using survey data Manzoor Elahi Chowdhury * Sarwar Uddin Ahmed. International Journal of Environment and Sustainable Development, 9, 91-113. http://dx.doi.org/10.1504/JJESD.2010.029965

d'Aquino, P., \& Bah, A. (2013). A Participatory Modeling Process to Capture Indigenous Ways of Adaptability to Uncertainty: Outputs From an Experiment in West African Drylands. Ecology And Society, 18(4). http://dx.doi.org/10.5751/ES-05876-180416

Danielsen, F. (2008). Local participation in natural resource monitoring: a characterization of approaches. Conservation Biology, 23(1), 31-42. http://dx.doi.org/10.1111/j.1523-1739.2008.01063.x

Davidar, P. (2010). Assessing the extent and causes of forest degradation in India: Where do we stand? Biological Conservation, 143(12), 2937-2944. http://dx.doi.org/10.1016/j.biocon.2010.04.032

De Herdt, T., \& Bastiaensen, J. (2004). Aid as an encounter at the interface: the complexity of the global fight against poverty. Third World Quarterly, 25(5), 871-885. http://dx.doi.org/10.1080/0143659042000231992

De Koning, J., \& Cleaver, F. (2012). Institutional bricolage in community forestry: an agenda for future research. In B. Arts et al. (Eds.), Forest-people Interfaces: Understanding Community Forestry and Bio-cultural Diversity (p. 292). Wageningen, The Netherlands: Wageningen Academic Publishers. http://dx.doi.org/10.3920/978-90-8686-749-3_17 
Djeumo, A. (2001). The Development of Community Forests in Cameroon: Origins, Current Situation and Constraints. London, UK.

Dressler, W. (2010). From hope to crisis and back again? A critical history of the global CBNRM narrative. Environmental Conservation, 37(1), 5-15. http://dx.doi.org/10.1017/S0376892910000044

Ezebilo, E. E. (2012). Community forestry as perceived by local people around Cross River National Park, Nigeria. Environmental Management, 49(1), 207-18. http://dx.doi.org/10.1007/s00267-011-9765-6

Ezzine De Blas, D. (2009). External Influences on and Conditions for Community Logging Management in Cameroon. World Development, 37(2), 445-456. http://dx.doi.org/10.1016/j.worlddev.2008.03.011

Ezzine de Blas, D., Ruiz-Pérez, M., \& Vermeulen, C. (2011). Management Conflicts in Cameroonian Community Forests. Ecology And Society, 16(1).

Holt-Jensen, A. (1999). Geography, History and Concepts: A students' Guide (3rd Edition, p. 228). London: Sage Publications.

Maryudi, A. (2012). Back to basics: Considerations in evaluating the outcomes of community forestry. Forest Policy and Economics, 14(1), 1-5. http://dx.doi.org/10.1016/j.forpol.2011.07.017

Minang, P. A. (2003). Assessing Participatory Geographic Information Systems for Community Forestry Planning in Cameroon: A Local Governance Perspective. International Institute for Geo-information Science and Earth Observation.

Ndibi, B. P., \& Kay, E. J. (1999). Measuring the local community's participation in the management of community forests in Cameroon, p. 271.

Ngendakumana, S. (2013). Rethinking Rights and Interests of Local Communities in REDD ${ }^{+}$Designs: Lessons Learnt from Current Forest Tenure Systems in Cameroon. ISRN Forestry, 2013, 1-14. http://dx.doi.org/10.1155/2013/830902

Nkemnyi, M. F. (2013). Making hard choices: balancing indigenous communities livelihood and Cross River gorilla conservation in the Lebialem-Mone Forest landscape, Cameroon. Environment, Development and Sustainability, 15(3), 841-857. http://dx.doi.org/10.1007/s10668-012-9416-y

Nkemnyi, M. F., Koedam, N., \& De Vreese, R. (2011). Livelihood and Conservation: Reconciling Communities' Livelihood needs and Conservation Strategies in the Bechati forest area, Western Cameroon. Saarbrücken, Germany: LAMBERT Academic Publishing.

Oyono, P. R. (2005). Profiling Local-Level Outcomes of Environmental Decentralizations: The Case of Cameroon's Forests in the Congo Basin. The Journal of Environment \& Development, 14(3), 317-337. http://dx.doi.org/10.1177/1070496505276552

Oyono, P. R., \& Efoua, S. (2006). La représentation environnementale au Cameroun: une exploration des liens entre les choix institutionnels, la démocratie locale et les résultats de la gestion décentralisée des forêts. Africa Development, XXXI(2), 149-184.

Oyono, P. R., Samba, S. K., \& Biyong, M. B. (2012). Beyond the decade of policy and community euphoria: The state of livelihoods under new local rights to forest in rural Cameroon. Conservation and Society, 10(2), 173. http://dx.doi.org/10.4103/0972-4923.97489

Pendergast, S. M., Clarke, J. A., \& Van Kooten, G. C. (2011). Corruption, Development and the Curse of Natural Resources. Canadian Journal of Political Science, 44(2), 411-437. http://dx.doi.org/10.1017/S0008423911000114

Ribot, J. C., \& Peluso, N. L. (2003). A Theory of Access. Rural Sociology, 68(2), 153-181. http://dx.doi.org/10.1111/j.1549-0831.2003.tb00133.x

Samndong, R. A., \& Vatn, A. (2012). Forest related conflicts in South-East Cameroon: causes and policy options. International Forestry Review, 14(2), 213-226. http://dx.doi.org/10.1505/146554812800923336

Sanginga, P. C., Ochola, W. O., \& Bekalo, I. (2010). Natural Resource Management and Development Nexus in Africa. In W. O. Ochola, P. C. Sanginga, \& I. Bekalo (Eds.), Managing Natural Resources for Development in Africa: A Resource Book (p. 571). Nairobi, Kenya: International Institute of Rural Reconstruction (IIRR).

Singer, B. (2008). Cameroonian forest-related policies: a multisectoral overview of public policies in Cameroon's forests since 1960. France: Institut d'Études Politiques and CIRAD. http://www.b-singer.fr/pdf/Forest_Policies_in_Cameroon.pdf. 
Vliet, N. Van. (2010). Participatory Vulnerability Assessment in the Context of Conservation and Development Projects: A Case Study of Local Communities in Southwest Cameroon. Ecology And Society, 15(2).

World Bank. (2007). The Nexus Between Infrastructure and Environment: From the Evaluation Cooperation Group of the International Financial Institutions. Washington, DC.

Yufanyi Movuh, M. C. (2012). The Colonial heritage and post-Colonial influence, entanglements and implications of the concept of community forestry by the example of Cameroon. Forest Policy and Economics, 15, 70-77. http://dx.doi.org/10.1016/j.forpol.2011.05.004

Yufanyi Movuh, M. C. (2013). Analyzing the Establishment of Community Forestry (CF) and Its Processes Examples from the South West Region of Cameroon. Journal of Sustainable Development, 6(1), 76-89.

Yufanyi Movuh, M. C., \& Schusser, C. (2012). Power, the Hidden Factor in Development Cooperation. An Example of Community Forestry in Cameroon. Open Journal of Forestry, 2(4), 240-251. http://dx.doi.org/10.4236/ojf.2012.24030

Zoa, M. (2009). Community forests: Reconciling customary and legal concepts. In M. C. Diaw, T. Aseh, \& R. Prabhu (Eds.), In Search of Common Ground: Adaptive Collaborative Management in Cameroon (p. 500). Bogor, Indonasia.

\section{Notes}

Note 1. Permanent forests include those assigned for natural parks, wildlife sanctuary and forest reserved.

Note 2. Cameroon population: http://www.tradingeconomics.com/cameroon/population-imf-data.html (accessed 27/10/13)

\section{Copyrights}

Copyright for this article is retained by the author(s), with first publication rights granted to the journal.

This is an open-access article distributed under the terms and conditions of the Creative Commons Attribution license (http://creativecommons.org/licenses/by/3.0/). 